\title{
Dependence of amorphous silica surface speciation on electric double layer (EDL) overlap in confinement
}

G. C. COPELAND*'; A. T. JACOBSON $;$ J J. P. KASZUBA ${ }^{12} ;$ J.C. DEWEY'; S. H. RISBUD ${ }^{3}$

Geology \& Geophysics, Univ. of Wyoming, Laramie, WY, USA (*correspondence: gcopelan@uwyo.edu)

${ }_{2}$ School of Energy Resources, Univ. of Wyoming, Laramie, WY, USA

${ }^{3}$ Materials Science \& Engineering, UC-Davis, Davis, CA, USA

Solid-liquid interactions in nanoconfinement often differ from their bulk counterparts. One such interaction is speciation on a material surface within an electrolyte solution. It remains unclear if surface speciation differs in nanoconfinement due to EDL overlap, material composition, pore structure, or combinations thereof. Different materials have shown varying degrees of surface speciation changes in nanoconfinement, from negligible up to $87 \%$ difference $[1,2]$. This potential change in surface chemistry can affect adsorption of metals and wetting characteristics of NAPLs and oils, major processes considered in environmental management and resource exploration fields $[1,2,3]$. Constraining which combinations of aforementioned conditions cause changes in surface speciation will help predict types of solid-liquid interactions that may occur given system-specific characteristics.

Synthesized amorphous silica aerogel with an average pore diameter of $19 \mathrm{~nm}$ and cylindrical pores is used to study effects of nanoconfinement on amorphous silica surface speciation with a known pore geometry. Potentiometric titrations are performed on $0.1 \mathrm{~g}$ of crushed aerogel in $0.001,0.01,0.1$, and $1 \mathrm{M} \mathrm{KNO}_{3}$ solutions at $20^{\circ} \mathrm{C}$ and 0.8 bar. Solutions are titrated from $\mathrm{pH} 11$ to 2 with $0.1 \mathrm{M} \mathrm{HNO}_{3}$. Surface charge density is calculated from titration data and fitted to CCM and CEM surface complexation models to derive surface protonation constants. These values will be compared between models and to those of bulk silica.

Surface potential and solution potential near the aerogel surface are calculated at experimental conditions to determine if the EDLs from pore walls overlap one another. EDLs for $0.001 \mathrm{M}$ and $0.01 \mathrm{M} \mathrm{KNO}_{3}$ do overlap, wheras those for $0.1 \mathrm{M}$ and $1 \mathrm{M}$ do not overlap. Protonation constants will be compared against EDL calculations to determine if EDL overlap correlates with changes in surface speciation.

[1] Stamberg et al. (2003) Colloids and Surfaces A: Physicochem. Eng. Aspects 221, 149-162. [2] Wang et al. (2002) Journal of Colloid and Interface Science 254, 23-30. [3] Brady and Thyne (2016) Energy Fuels 30, 9217-9225. 